Journal of Computer Sciences 1(4 ): 488-494, 2005

ISSN 1549-3636

(C) Science Publications, 2005

\title{
E-Learning under WebCT
}

\author{
Z.A. Al-Khanjari, N.S. Kutti and H. A. Ramadhan \\ Department of Computer Science, College of Science, Sultan Qaboos University, \\ P.O. Box 36, Al-Khodh 123, Sultanate of Oman
}

\begin{abstract}
With the introduction of Web-Based Instruction (WBI) the traditional classroom-based higher education could be made more effective form of instruction. But the studies have shown the negative results $^{[1]}$. On the other hand the distance education has derived the direct benefit of WBI through extending classroom instruction in online to reach every remote student. However researchers have identified reasons for the lack of effectiveness of WBI in both classroom and distance education. WBI along with a suitable learning strategy is a tangible solution. As the learning strategy based entirely on the constructivists approach may not be feasible for the students with less or no experience our studies recommend a hybrid strategy called Integrating Multiple Learning Strategies (IMLS) that can be implemented to achieve the effect of e-Learning. This study presents the issues identified with the WBI-based learning paradigm and WebCT, various learning approaches and feasible e-Learning models around WebCT for IMLS approach.
\end{abstract}

Key words: Course management system, web-based instruction, cognitive skill, instruction-based, experiment-based, problem-based and constructivists approach, transmitted, negotiated and harvested knowledge

\section{INTRODUCTION}

The tendency to use WBI in the current educational context is growing fast. WBI in relation to e-Education seems to provide an alternative solution in improving the traditional classroom-based education. Particularly the distance education finds a better on-line solution by using WBI. Researchers predict that its influence would soon change the current pattern of education completely ${ }^{[2]}$. According to ${ }^{[3]}$ WBI is an innovative approach for delivering instruction in online using the WWW as the instructional delivery system. Its rich information source and its universal access creates a suitable resource-based platform for both students and instructors in learning perspective. What is more important is its interactive and collaborative nature that allows a community of learners to exchange knowledge, ideas and even their learning skills. ${ }^{[4]}$

The Course Management Systems (CMS) like WebCT come with a set of tools basically for supporting instruction-based education. The instructor-based approach followed in the traditional education is basically an instructor-centered model where the instructor acts as a knowledge source and the students as the knowledge receivers It is found that instruction-based approach provides a static mode of education in which the self motivation is not considered as an essential factor to carry out learning process.
When WBI is used with instruction-based approach, it allows students to view the e-Materials in online with no effect in their learning. The facility is no more than supplying printed text books to students. To make the WBI effective particularly in the absence of face to face contact with their instructors a self-learning or motivated learning among students should be initiated. The solution for this can be found through the use of WBI tools (such as WebCT) to carry out the interactive and collaborative activities. This leads to a transformation of simple use of CMS from teaching environment to an interactive and collaborative environment for student-centered learning ${ }^{[1]}$.

Studies clearly show that the students with less or no experience in life need continual guidance while they are attempting to learn by themselves. The guidance required for self learning is in multidimensional form, namely step-wise goal specification, private interaction with reading materials, social interaction with instructors and other learners, instructor mediation, etc. The solution to this problem is to provide a proper and complete on-line course environment in a CMS. CMS should integrate all necessary elements (e.g. instructional materials, courserelated software tools and information systems, tools for interactive and collaborative communication) into single online entity that is not only bringing the related communities together, but also acting intelligently

Corresponding Author: Z.A. Al-Khanjari, Department of Computer Science, College of Science, Sultan Qaboos University, P.O. Box 36, Al-Khodh 123, Sultanate of Oman E mails: zuhoor@squ.edu.om 
in training students in their learning skill. An attempt has been made by our research team to create an eLearning environment by using the facilities available in WebCT. Introducing entirely the constructivists approach to the less matured students may totally fail in achieving the results. Our work emphasizes in applying combinations of several approaches (e.g. instructionbased problem-based, experiment-based, etc) in multiple steps to achieve ultimately the independent learning. The hybrid scheme leads to Integrating Multiple Learning Strategies (IMLS) to evolve a feasible student-centered learning (e-Learning) model.

This study presents an investigation carried out in finding a feasible solution for implementing a learningbased pedagogy using WebCT in SQU. Section 2 of this paper gives a conceptual definition of the term eLearning. This section also analyzes the required skills with students to enable their self-learning. Section 3 maps out various learning strategies for the student-centered learning. Section 4 presents an overview of the existing online environment supported by WebCT in SQU. Section 5 explores various issues with respect to e-Learning implementation using WebCT environment. Section 6 describes a learning environment based on IMLS to experiment on the student-centered learning process. Section 7 proposes some e-Learning models around WebCT that can be used to achieve the constructivists approach gradually.

\section{CONCEPT OF E-LEARNING}

The traditional education is basically an instructorcentered education. The instructors are considered as knowledge sources and course planners. Students are considered as simply the information receivers. They follow the instructions of the instructors in the process of learning. When the WBI is considered the instructors deploy all their instructions in on line and expect their students to proceed with their learning in the absence of any interaction. The concept of e-Learning can be explained as self-directed and resource-based learning. Students should possess cognitive skills (i.e. negotiation of meaning, reflective analysis and metacognition) ${ }^{[5]}$, aptitude to work in the self-learning and confidence in information seeking and evaluation to learn independently ${ }^{[6]}$. In general, the learning process involves in developing the learning skill first and then applying the same to learn the given subject. To develop the learning skills a suitable learning environment must be provided to students (Figure 1). If a CMS is used as web-based learning tool, then it should provide a proper e-Learning environment. Such an environment has the following characteristics.

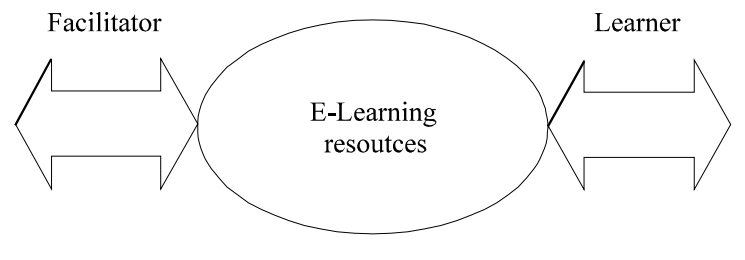

Fig. 1: E-learning environment

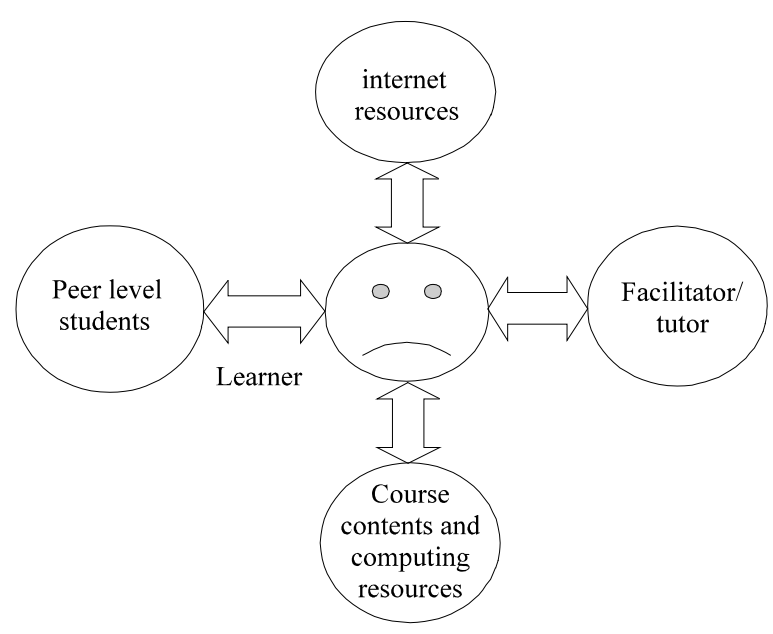

Fig. 2: E-learning solution

- No face-to-face interaction.

- Students depend upon the on line resources only.

- Students are expected to have access to Internet and then a CMS to reach the on line resources.

- The CMS must provide (groupware) tools supporting for collaborative and interactive learning.

According to the constructivists approach cognitive skills can be developed in an interaction-rich environment. The types of interactions can $\mathrm{be}^{[7]}$ :

- Interaction with instructors

- Interaction with peer group

- Interaction with specialists

- Interaction with resources (course related testing tools, newsgroup, listserv, forum, database, WWW, virtual lab, etc)

On top of all the above requirements e-Learning requires students with sufficient background to use the environment in their knowledge-building activity. Figure 2 shows the e-Learning solution.

\section{LEARNING STRATEGIES}

The classroom education introduced Instructionbased approach to transfer specified knowledge to 
students. In this approach instructors act as knowledge source and take the responsibility of delivering that knowledge to students. Students in this approach simply follow the instructions given by their instructors. Instructions are carried out through supplying course outlines, list of reading materials and study guide, assignments, quizzes, etc. Textbooks and lecture notes represent the main sources of course knowledge. Assignments represent small problems and by solving those problems students understand the concepts explained in the lectures. Tutorials are used as a form of guidance to help students in their homework. Among the limitations of this approach, the following are stated:

- Students learning progress simply depends upon the instructor-specified instructions.

- Students have no opportunity to gain any knowledge of self-learning directly.

- Part of knowledge gained by students depends upon the instructor knowledge around a course.

Enquiry-based approach considers the interactive mode with multiple ways as an important ingredient. This is an enhancement over the instruction-based approach where there is only one way communication. The interaction between the student and the instructor as well as with other students is encouraged. Unlike the instruction-based approach this approach provides twoway communication.

Experiment-based approach is more practical oriented learning and it helps learners to understand the concepts clearly and at the same time gain experience in solving problems practically. Usually practical oriented courses belong to this approach.

Problem-based approach is more effective than the previous approaches particularly in training students in a group discussions and solving the problems. The instructor can select problems for discussions such that the discussions (or forums) can be helpful in exploring the concepts related to the courses.

Project-based approach is an extension to the problem-based approach. Here, students are allowed to form into several groups and each group is allowed to select a problem in a special area. The instructor acts as supervisor of the projects. The interaction between the students and the instructor is minimum, the interaction with other information resources become more significant. Students gain the following skills:

- Independent thinking skill that includes analyzing a problem, identifying the goal, identifying and adopting appropriate strategies to achieve the goal

- Research skill through identifying the need for information, sources of information and acquiring those information efficiently.
- Management skill (i.e. time management for completing the undertaken task)

This approach is at present used in some of the courses (e.g. System Analysis and Design, Software Engineering and final year project) of undergraduate program in Computer Science. This is an added value to the instruction-based traditional education.

Finally, the constructivists approach creates a balance of independent, interactive and interdependent environment in which students gain the experience of self-learning. Constructivists ${ }^{[8]}$ believe that students construct their own knowledge and understanding by using their cognitive skills. Students' prior experience and the derived knowledge and understanding help their self-learning process. As students learn, they constantly engage in the process of revising their prior knowledge structure based on new experience.

This approach introduces a major step in transforming the instructor-centered classroom education into learner-centered inquiry based education. Instructors become facilitators or moderators in this approach. This approach allows students to involve effectively with a dynamic knowledge building activity. The effectiveness of this approach depends upon the richness of the learning environment provided around the student community. The required activitiesfor students in this approach include: interaction with instructors from time to time, collaborative and cooperative activities with peer groups, conducting literature survey and management of resources (i.e. time). Students gain the following skills:

- Developing new learning styles

- Problem solving abilities

- Ability to communicate with instructors

- Ability to interact with peer groups

- Benefit of group discussions

- Ability to guide peer group

- Experience to become life-long self-trained and responsible learners

Constructivists approach is an ideal solution for eLearning. But it requires a constructivistic environment with appropriate tools for effective knowledge acquisition. Tools needed for this model include mechanisms to interact with the instructor, the peers and the experts in the same fields, tools to conduct group discussions, access mechanisms to participate in the external forums, etc.

Most recent CMS portals including WebCT come with basic facilities to support some form of eLearning. To implement the constructivists approach the existing mechanisms need to be upgraded and/ or new mechanisms are to be added to CMS. More detailed discussion on WebCT is presented in the following section. 


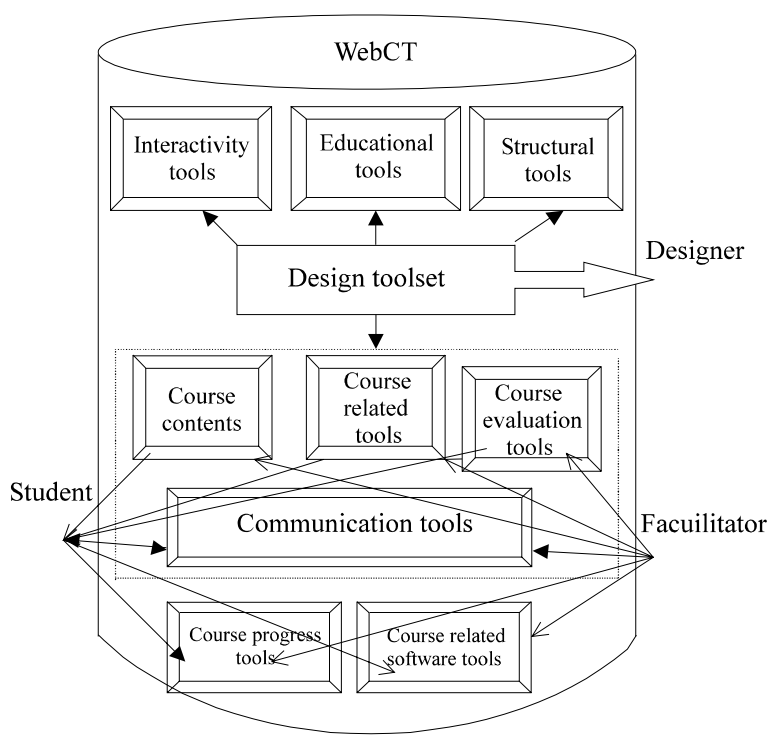

Fig. 3: WebCT facilities for e-learning environment

\section{THE WEBCT PLATFORM}

WebCT features for e-learning: WebCT comes with a set of basic facilities to prototype an e-Learning environment (Figure 3). It allows instructors to organize their online courses in a structured manner. The course information can be structured in a hierarchical manner forming a course-tree. A node in the tree could be an organizer page, a content page or a URL page. A content page simply carries any document. A URL page is created to establish a link to an external reference. An organizer page is like a directory in a file system. It can be used to group the related pages and tools. In summary, WebCT provides the interactivity, educational tools and structural tools. (A good review of WebCT can be found $\mathrm{in}^{[9]}$ ). Interactive tools within $\mathrm{WebCT}$ include:

- E-mail tool that allows a student to communicate with instructor and other students in a course. Students can use this facility as an asynchronous discussion tool.

- Discussion tool allows students and instructors to manage forums on many topics. On each topic messages from the participants are posted for the purpose of interchanging ideas.

- Chat tool that allows a synchronous communication between instructors and students and among students. It is a real-time tool, which emulates face-to-face communication.

- Presentation tool that allows the project groups to share the allocated presentation area for group editing. This is also an asynchronous tool suitable for discussion among small groups.
- Reference page or database is maintained by the instructor to allow students to share the list of references related to a course. For example instructors can supply useful reading lists including URL-links to useful web sites. This tool provides an asynchronous and one-way interaction between instructors and students.

- Glossary is another reference tool maintained by the instructor to help students in finding the definitions of various course related terms.

- Course Calendar is also a form of communication tool used by the instructor to time table the learning activities.

Educational tools include student evaluation tools (e.g. Timed Online Quiz types i.e. True/ False, Multiple Choice, Matching, Fill-in Blank, Short Answer), student progress tools (e.g. Self Test, My Grade and Progress Tracing). The structural tools include organizer page, URL page and presentation tool.

Figure 3 shows a general overview of WebCT as an e-Learning tool. The portal has two distinct views: student view and designer's view. Instructors use the designer's view to design their courses and/ or from time to time update the designed course. The instructors can also control the students' access to the course pages using the designer's view option. Students who are registered in a course are granted to access the students' view to read instructions, course materials, various interactive tools and grades as shown. They can also make submissions/ resubmissions of assignments and communicate with their instructor as well as with their co-students.

WebCT set up in SQU: The Centre for Information Systems (CIS) at Sultan Qaboos University (SQU) is responsible for maintaining the university network along with all academic-support-software resources. The center for Educational Technology (CET), a user of CIS facility has been trusted with the responsibility of providing necessary university-wide educational services including the e-Learning facility via the WebCT portal. The current WebCT environment does not allow students for testing all types of programming tasks within WebCT. Students in general access their software tools either from the centrally controlled network resources or from their host systems.

\section{Limitations of WebCT-based existing e-learning} environment: Although WebCT provides a range of facilities, e-Learning requirements cannot be fulfilled directly by using those facilities. First of all some of the

tools that are available in WebCT are stand alone and don't act cohesively in the process of student learning. 
For example, students have to open the pages that contain lecture notes, read the required sections and then close the pages before they can open other tools (e.g. glossary for reference or discussion tool for negotiation) on the read materials. Students may have to shuttle between the tools during their interaction with resources. They may eventually fail to maintain their interest in their self-learning. Secondly, the static nature of lecture notes (or any other material) does not create a dynamic environment to help grasping the knowledge effectively. It is no more than reading any textbook. Thirdly, WebCT does not support courserelated software tools directly. In this situation students have to come out of WebCT to carry out any experiment during reading. Similarly students find difficulty in using the Self Test tool simultaneously during reading. Such provisions are not available with WebCT. However, WebCT can be used to emulate an e-Learning environment suitable for students to begin their cognitive skill building process. Particularly with its rich communication facilities a prototype constructivist environment in support of e-Learning can be realized within WebCT.

Extended e-learning environment: We have introduced a mechanism to enhance WebCT system in order to plug-in course related software tools with each course registered in $\mathrm{WebCT}^{[10]}$. This satisfies the availability of the resources in online. Instructors can add either vendor supplied tools or home grown tools to their courses. Students need not depend upon the resources in their PCs. The plug-in mechanism can also be used to link software tools anywhere in the internet. It can even link to any other computer or network in the Internet (e.g. Unix Network). This satisfies a requirement of e-Learning environment.

Issues in implementing e-learning: The practical implementation of e-Learning environment faces several issues due to complex nature of some learning approaches and the limitations of CMS (in our case WebCT). With respect to learning paradigm the issues exist due to:

- School leaving students have no cognitive skills built during their school education.

- Instructors are trained in the instruction-based approach and may have little or no cognitive skill to develop and foster student Learning skill.

- Instructors have no confidence in changing their attitude.

- Instructors and students have no idea of eLearning.

- Uncertain environment using constructivists approach.

- Constructivists believe that "students independent learning" will become true soon and the future looks for a knowledge-based society.
The issues due to CMS are:

- Instructors and students lack Network Information and Communication Literacy (NICL).

- Instructors and students have no experience with web based e-Learning tools.

- There is no web-based CMS portal that can provide all required service tools in support of the e-learning environment.

\section{FEASIBLE E-LEARNING SOLUTION USING IMLS}

First the constructivists approach is the ideal one in building the learner's learning skills. But, not all students in higher education can fit in this approach. Due to the nature of issues listed above it may be difficult to apply the constructivists approach in one step. Particularly the undergraduate students with less or no cognitive skills need a gradual introduction to this approach $^{[1,11]}$. The overall approach may need two or more stages. In the first stage, the students can become familiar with the course management tool. In the second stage they would be able to build their cognitive skills using simple interactive environment. In the third stage, a collaborative environment can be exposed to students with the advanced tools. In the fourth stage, an interactive environment in a global community may be exposed to students. The following section elaborates the models recommended and proposed by us.

We can organize the knowledge types in a hierarchical manner and learners can gain all types of knowledge gradually through appropriate learning approaches. The knowledge acquired by a student in eLearning environment can be classified into transmitted knowledge acquired using instruction-based approach, negotiated knowledge acquired using the enquirybased, problem-based, experiment-based approaches, and group work-based approaches and harvested knowledge using the interaction with Internet resources $^{[6]}$. To start with the e-Learning process the instruction-based approach can be used as its first phase to become familiar with the CMS. In the next phase, the instruction-based approach with a limited interaction (e.g. using email) can be followed. With the confidence gained in the first two phases the next phase can include problem-based and experiment-based approaches by using few more interactive tools available in CMS. Similarly, every subsequent phase combines additional learning approaches that would gradually improve the students e-Learning capabilitiess.

\section{E-LEARNING MODELS}

A simple model (scheme one) is instruction-based approach using WebCT. This approach is almost same as the traditional instruction-based one except the usage 
of WebCT for transferring the knowledge from the instructor to students. In this scheme instructors put all course related contents and necessary instructions in the WebCT pages. Students can become familiar with various services provided by WebCT. The Syllabus, Calendar and email tools can be used as medium to carry the course outlines, goals and outcomes as well as instructions to guide the students.

- The course-outline specifying the contents, goals, outcomes and the significance of email-based interaction for the student progress.

- A study guide with multiple sessions. Each session contains instructions to:

read a section

view examples related to the section read Frequently Asked Questions (FAQ)

follow exercises related to the section perform a self-test related to the section

- Glossary tool as the keyword-definition database.

- Self-test tool with question database

- Email and Calendar tools as one-way communication to carry instructions from the instructor.

In the second model, the instructors should set up a framework that would encourage students to use enquiries in their cognitive skill. Students can use the email tool to interact with other students learners in the course as well as with their instructor. The enquiries and answers can be monitored by the instructor. From time to time the instructor can mediate the controversial situations. The instructor should plan using this enquiry-based approach such that it creates a learning atmosphere among the participants. It should further motivate students not only to participate freely in email discussions, but also to learn how effectively they can form the queries. The email interaction should be made as a compulsory mechanism in the mediation process. Its role must be recognized as the starter in building the student learning skill. How effectively the email interaction is going to induce the learning skill among students depend upon the cognitive skill of the instructor also. The facilities for this e-Learning environment may include the following:

- The course-outline specifying the contents, goals, outcomes and the significance of email-based interaction for the student progress.

- A study guide with multiple sessions. Each session contains instructions to:

read a section

view examples related to the section read Frequently Asked Questions (FAQ)

follow exercises related to the section perform a self-test related to the section

- Glossary tool as the keyword-definition database.
- $\quad$ Self-test tool with question database.

- Calendar to carry additional instructions particularly the event-based information.

- Email as discussion tool.

The third model includes the problem-based approach. It is assumed that the students have gone through the experiences of previous two models before learning through this model. This model enables both instructors and students to develop learning skills using the problem-solving approach in a somewhat rich interactive environment.

In addition to Email, students can use discussion and real-time Chat tools to solve the problems. Instructors can organize discussions (or forums) by formulating problems, initiating discussions on those problems and guiding the discussions. On each topic of the syllabus, instructor can maintain more than one discussion simultaneously. The facilities for this eLearning model include the following:

- The course-outline specifying the contents, goals, outcomes and the significance of email-based as well as discussion board based interaction for the student progress.

- A study guide with multiple sessions. Each session contains instructions to:

reading a section

viewing examples related to the section

viewing Frequently Asked Questions and

Answers (FAQA)

doing the exercises related to the section

performing a self-test related to the section

- Glossary tool as the keyword-definition database.

- Self-test tool with question database

- Email, discussion and Chat tools to conduct forums.

Instructors should play the role of a facilitator to develop the learning skill of the students using the discussion tool. Students will be able to develop their cognitive skill through the interaction provided by the forum. Here, the instructor can participate very actively in problem solving. This will increase the student confidence in problem solving.

The fourth model encourages independent learning using project-based approach. Instructors can form student groups, assign a separate exercise to each group and monitor their progress. The Presentation tool of WebCT can be used as a groupware tool. The instructor role here is more like a guide as well as a moderator. $\mathrm{He}$ or she can intervene when students are caught in deadlock. Moreover, students can consult any specialist on the Internet using email or interact with Internet resources through URL-linked interface. They are guided to map out what information is required and where in the Internet the information is available, etc. Students would effectively gain the skill how to target 
the required information from the Harvested Knowledge accumulated in the Internet. In this model, Instruction-Based, Enquiry-based, Experiment-based, Problem based and Project-based approaches are used to enable independent learning.

The extra facilities needed in WebCT are:

- Presentation tool for group work.

- Database of newsgroup lists, listserv lists, websites, etc that are useful for solving problems.

- Plugged-in tools for accessing newsgroups and listserv

- Plugged-in tools to browse through WWW and access various databases in the Internet.

- Student progress tracking tools.

The plug-in mechanism devised in SQU's WebCT can be used to access external resources ${ }^{[10]}$.

\section{CONCLUSIONS}

Instruction based approach by itself may not be sufficient to create an e-Learning environment. At the same time the constructivists approach cannot be applied entirely at the undergraduate level because of its complex nature. Gradually introducing e-Learning is the only feasible solution because of the dynamics involved in acquiring cognitive skills. WebCT comes with sufficient interactive facilities using which all the prototypical models of e-Learning explained in this study can be realized. WebCT in conjunction with classroom education can provide a feasible platform particularly for undergraduate students.

Students trained in the e-Learning will be life-long learners. They will be able to apply the acquired training in solving problems in their workforce. Moreover their self-organizational skill gained through e-Learning can improve their leadership quality indirectly. Facilitators role become multifold: they become managers in planning, specifying goals and outcomes; they are instructors in supplying course contents, lecture notes, assignments and tests; they become tutors in maintaining interactions; they become mediators in resolving deadlocks; finally they themselves become life-long learners while helping students to develop their cognitive skills. At the same time they are researchers in their own academic discipline.

By taking all these facts into consideration our work continues to implement some of the Computer Science courses using the above-mentioned models on the experimental basis.

\section{REFERENCES}

1. LaBonte, R., S. Crichton and D. Allison, Moderating tips for synchronous learning using virtual classroom technologies. http://www.odysseylearn.com/resource/emod.html

2. IDE, 1997. Innovations in distance education. The Report of Two Policy Symposia. http://www.cde.psu.edu /de/ide/policy.default.html.

3. Khan, B.H., Web-based Instruction (WBI): What is it and Why is it? In Web-based Instruction, Editor: B.H. Khan, Engelwood Cliffs, New Jersey: Educational Technology Publications. http://www.odysseylearn.com/ resource/emod.html

4. Daugherty, M. and B.L. Funke, University faculty and student perceptions of web-based instruction. http://www.odysseylearn.com/resource/emod.html

5. Phelps, R. and B. Kerr, 2004. Teachers and ICT: Exploring a metacognitive approach to professional development. Australian J. Educational Technology, 20: 49-68.

6. Gaimster, J. and D. Gray, 2004. Harvesting Knowledge: The role of the Internet in helping students to develop independent research skills-a case study.http://www.eurodl.org/materials/contrib. /2004/Gaimster_Gray.html

7. Swan, K., 2004. http://www.eurodl.org/materials/ contrib/2004/Karen.html

8. Jonassen, D., T. Mayes and R. McAleese, A Manifesto for a constructivist approach to technology in higher education. http://www.apu. gcal.ac.uk/clti/papers/TMPaper11.html.

9. Goldberg, M.W. and S. Salari, 1997. An update on WebCT (World-Wide-Web Course Tools)-a tool for the creation of sophisticated web-based learning environments. Proceedings of NAUWeb'97, Flagstaff, Arizona. http://star.ucc.nau.edu/ nauweb97/papers /goldberg/goldberg.html

10. Al-Khanjari, Z.A., N.S. Kutti and M. Hatam, 2005. An extended e-learning system architecture: integrating software tools within the e-learning portal. Accepted for publication in IAJI.

11. Mayes, D. and R. McAleese, A manifesto for a constructivist approach to technology in higher education. http://apu.gcal.ac.uk /clti /papers/ TMPaper11.html 